\title{
Hereditary index finger polydactyly: phenotypic, radiological, dermatoglyphic, and genetic findings in a large family*
}

\section{METIN ATASU}

From the Departments of Pediatrics and Clinical Genetics, School of Medicine, Hacettepe University, Ankara, Turkey

Summary. Index finger polydactyly in a Turkish family is reported. The transmission of the malformation fits the pattern of regular autosomal dominant inheritance. Some of the affected individuals had one or two phalanges on their first digits, but all had triphalangeal second fingers. Subjects with polydactyly had very interesting dermatoglyphs, such as an extra $a$ triradius under the supernumerary index finger, the proximal radiant of this triradius (an extra $A$-line) ending on the radial border of the hand, and arch tibials in the hallucal areas. The carpal bones, beginning with os multangulum majus, or alternatively with the extra one were articulated with two metacarpals. A similar finding was found in the feet.

McKusick (1971) has classified the types of polydactyly in his catalogue. One of these is polydactyly, preaxial III or index finger polydactyly. According to McKusick these type polydactyls show one or two triphalangeal thumbs instead of one.

In the present report the phenotypic, radiological,

Received 4 March 1976

* The dermatoglyphs in the paper were given at the 6th Bartos Symposium on Dermatoglyphics, Bratislava, 1974; the other parts of the paper given at XIIIth Czechoslovak Anthropological Congress, Brno, 1975. and genetic observations in a Turkish family showing index finger polydactyly, are described.

\section{Case reports}

The living members of the family presented here come from near Ankara. The pedigree of the family is shown in Fig. 1. The mother of the proband and her brothers and sister could give no description of family members in the earlier generations.

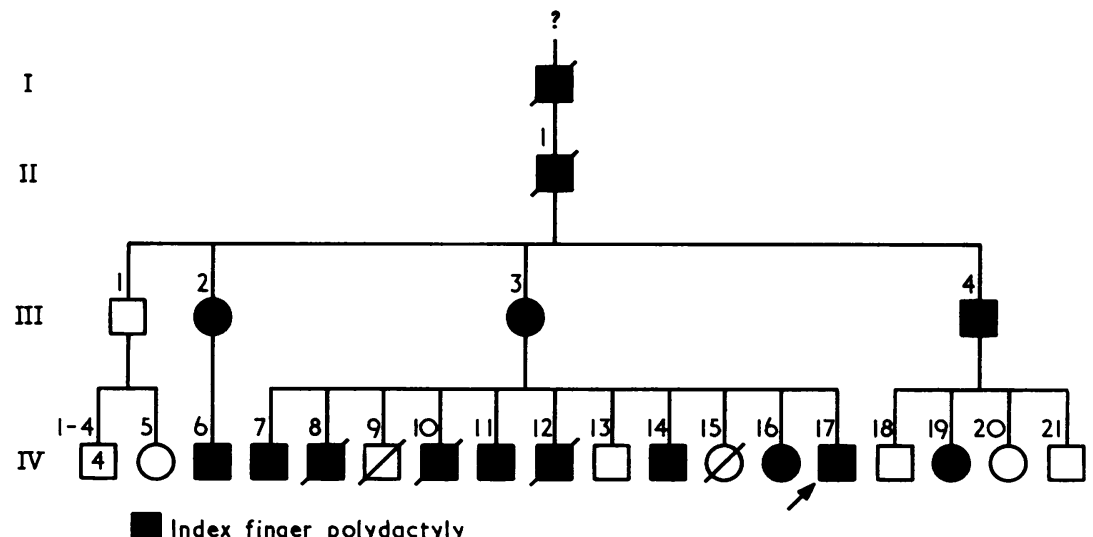

Index finger polydactyly

FIG. 1. The pedigree of the family with index finger polydactyly. 
Fifteen affected individuals are known in 4 generations; 20 family members in 2 generations, 10 affected and 10 normal have been examined.

The mother and maternal aunt who were affected with index finger polydactyly had peptic ulcer. The other affected family members were normal in both health and intelligence. IV.8, IV.9, IV.10, IV.12, and IV.15 died when they were young as a result of infectious diseases.

\section{Phenotypic and radiological findings}

The photographs of the hands and feet of IV.6 are shown in Fig. 2. All the digits and toes of the affected patient were well developed as were those of the other polydactylous individuals presented here, except for the left first digit of the proband. The first digits of IV.11, the sixth toes of III.4, and the first toes of IV.16 were amputated.
The affected individuals wrote using their fists, $\stackrel{\mathbb{Q}}{\stackrel{\circ}{ }}$ second, third, and fourth fingers, and by grasping $\Omega$ the pencil between the second and third fingers. They shook hands by grasping them between the second and the third fingers.

The radiographs of the hands and feet of III.4, IV.7, IV.11, IV.14, and IV.17 are shown in Appendix 1. The important records are presented in the same appendix.

\section{Dermatoglyphic findings}

The digital type and main lines of the dermal ridges on both hands and feet of the affected individuals are shown in Appendix 2.

\section{Genetics}

The transmission of index finger polydactyly in the family presented fits the pattern of regular autosomal dominant inheritance. The proportion of

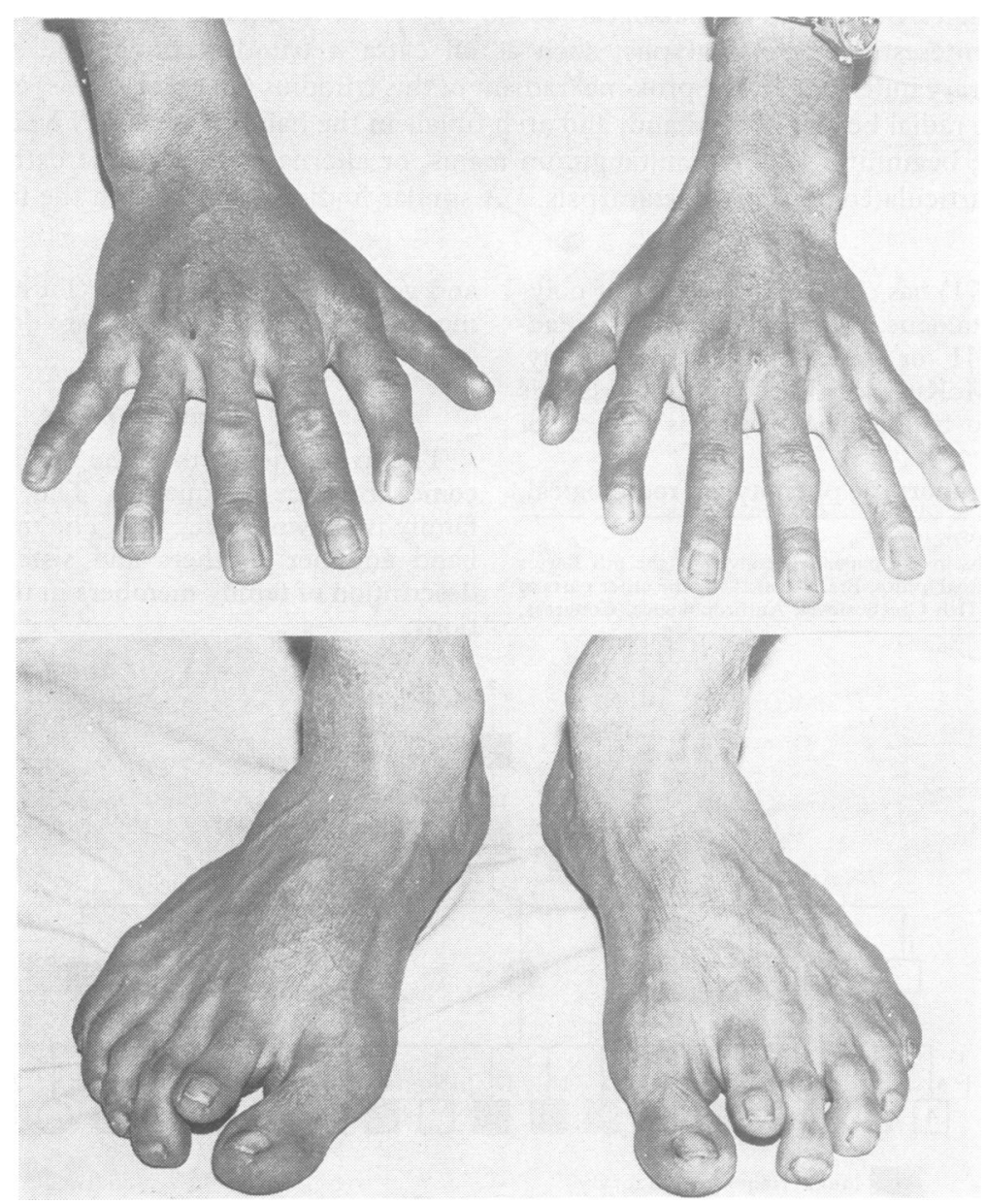

FIG. 2. The photographs of the hands and feet of IV.6. 
affected and normal offspring of the affected individuals does not differ significantly from the expected 1:1 ratio. Some of the affected cases had one or two phalanges on their first fingers, but all had triphalangeal second fingers and preaxial polydactyly (Appendix 1, Table 1).

\section{Discussion}

In 1931 Manoiloff reported a case with index finger polydactyly. According to the author the condition had been transmitted for 700 years and inherited as a simple autosomal dominant trait.

Swanson and Brown (1962) have described a family with triphalangeal thumbs and thought that the triphalangism of the thumb might be the result of a duplication or slitting of a thumb phalanx, whether it is proximal or distal; an interposed bony remnant or aborted primordial radial duplication of thumb phalanges; and absence of a normal radial ray, with reduplication of one of the remaining rays.

Kanavel (1932) has pointed out that in some instances the triphalangeal thumbs have been called extra index fingers.

Wood (1970) has reported 4 cases with index finger polydactyly and syndactyly and supported Kanavel's (1932) idea.

In the summary, the malformation in the thumb polydactyly is reduplication of all or part of the components of a thumb. In polydactyly of a triphalangeal thumb, the thumb has three phalanges with reduplication of all or part of its components. In index finger polydactyly, the thumb is present and the index finger is duplicated. Now, we can go further. The phenotypic and radiological findings of the polydactylous individuals presented here show that the type of the condition is index finger polydactyly. But one of them has a distal phalanx on his rudimentary left thumb which could be a duplicated distal phalanx of a thumb, the other has an extra os multangulum majus and most of them have triphalangeal first digits on one hand or both hands supporting Swanson and Brown (1962), Kanavel (1932), and Wood (1970)'s assumptions. However, Penrose (1971) had pointed out that the extra digit necessitates an extra triradius. Besides, Temtamy (1966) has reported that the dermatoglyphs in index finger polydactyly are most important findings in the diagnosis of the malformation, e.g. an extra $a$ triradius and an $A$-line are present on the palms of the individuals with index finger polydactyly. The same findings have been observed in the polydactyls presented here. In other words, they have an extra $a$ triradius under the extra index finger and have $A$-lines terminating on the radial borders of the hands. Surprisingly, some of the affected individuals have the proximal radiants of the third digital triradii ending on region 1 of the palms. On the other hand, it should be noted that Belelli $(1937,1939)$ has described the dermatoglyphs of two brothers with triphalangeal thumbs. The mother had an extra thumb. Both brothers had radial loops on the thumbs. The alignment of the ridges in the proximal part of the palms was transverse. Some of the polydactyls presented here also have radial loops on the first and (or on the second and) or third finger tips. But, the ridge alignments are vertical and the thenar eminences are poorly developed and there is no pattern in the thenar first interdigital areas.

The most interesting dermatoglyphic finding of the individuals with polydactyly is an arch tibial in the hallucal areas. This type configuration is peculiar to Down's syndrome and rare in normals. The frequencies of this type in the hallucal areas of Turkish control individuals are 0.3 per cent on both feet. In addition, it should be pointed out that there is an extra $a$ triradius under the supernumerary toes and also an extra $A$-line terminating on the tibial borders of feet of subjects with polydactyly. These could be affected forming the arch tibials.

As a result, the malformation presented here is index finger polydactyly associated with preaxial polydactyly.

\section{REFERENCES}

Bellelli, F. (1937). Su alcuni casi di pollice a tre falangi. From Bollettino della Scuola Superiore di Polizia e dei Servizi Tecnici Annessi, 24, 25, and $26(1934,1935$, and 1936).

Bellelli, F. (1939). Un nuovo caso di pollice a tre falangi bilaterale. Riforma Medica, 18, 1001-1002.

Kanavel, A. B. (1932). Congenital malformations of the hands. Archives of Surgery, 25, 281-320.

McKusick, V. A. (1971). Mendelian Inheritance in Man: Catalogs of Autosomal Dominant, Autosomal Recessive, and X-linked Phenotypes, 3rd ed. Johns Hopkins Press, Baltimore.

Manoiloff, E. O. (1931). A rare case of hereditary hexadactylism. American fournal of Physical Anthropology, 15, 503-508.

Penrose, L. S. (1971). Dermatoglyphics and medicine. Documenta Geigy: Acta Clinica, 13, 22.

Swanson, A. B. and Brown, K. S. (1962). Hereditary triphalangeal thumb. Fournal of Heredity, 53, 259-265.

Temtamy, S. A. (1966). Genetic factors in hand malformations Unpublished doctoral dissertation, Johns Hopkins University.

Wood, V. E. (1970). Duplication of the index finger. Fournal of Bone and foint Surgery, 52-A, 569-573. 


\section{APPENDIX 1}

Radiographs of some individuals with index finger polydactyly



FIG. 1. Radiograph of the hands of III.4.



Fig. 2. Radiograph(of the feet of III.4.

응

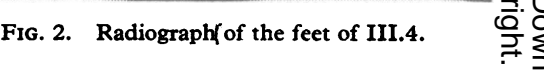



FIG. 3. Radiograph of the hands of IV.7.



FIG. 4. Radiograph of the feet of IV.7. 




FIG. 5. Radiograph of the feet of IV.11.

FIG. 6. Radiograph of the feet of IV.14.
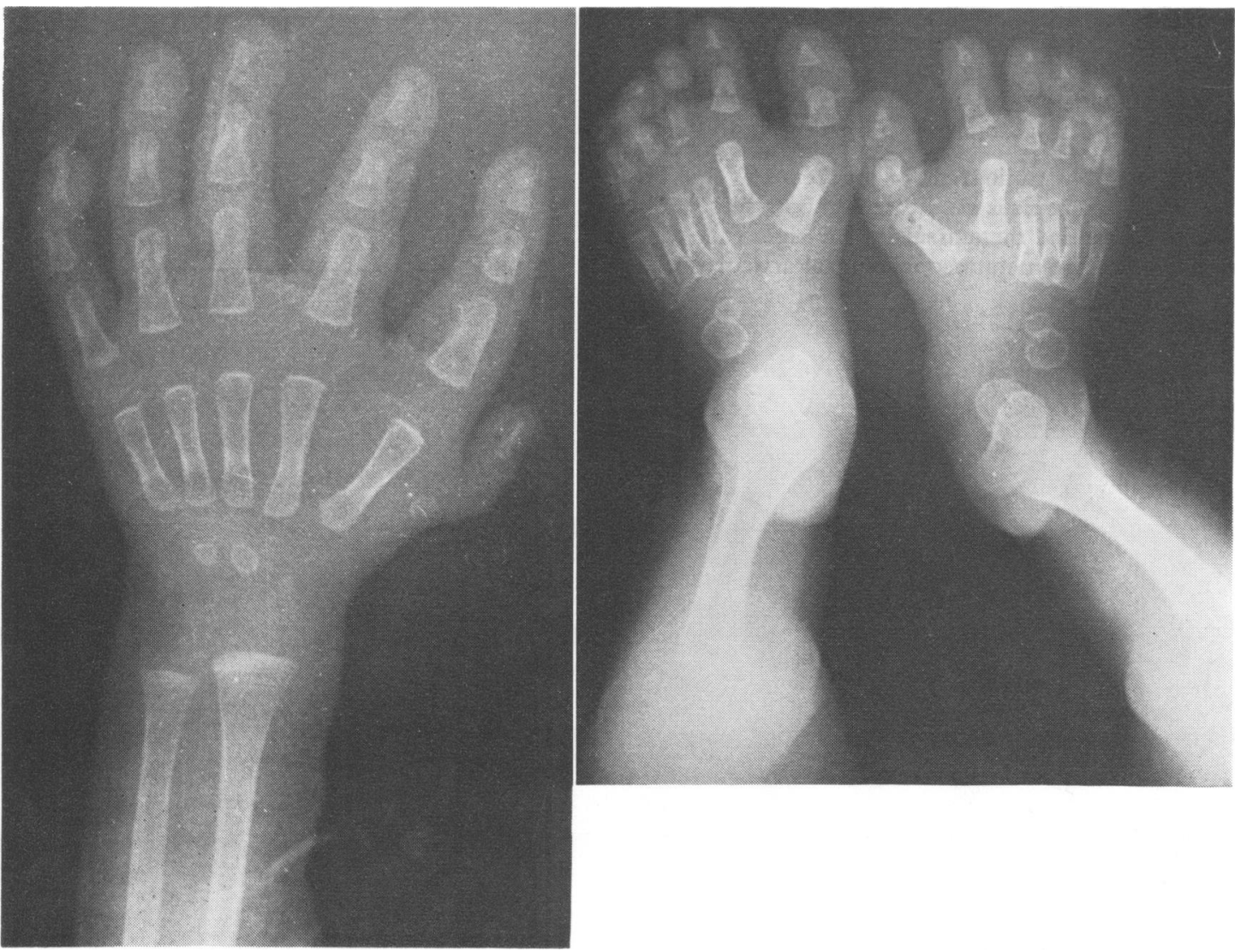

FIG. 7. Radiograph of the left hand of IV.17.

FIG. 8. Radiograph of the feet of IV.17. 


\section{Descriptions of radiographs}

Fig. 1. A 35-year-old man, III.4. The radiograph of the hands. There is a triphalangeal first digit with ulnar deviation of the second and third phalanges on the left hand. In contrast, on the right the first digit has two phalanges. All the other digits have three phalanges. The carpal bones in both rows are normally placed. Their number does not increase. Beginning with os multangulum majus, they articulate with two metacarpals instead of one.

Fig. 2. The radiograph of the feet of III.4. The sixth toes are amputated. The first and second metatarsals articulate with the first os cuneiformis. The row and the number of them are normal.

Fig. 3. 17-year-old male, IV.7. The radiograph of the hands. On the left hand, the first digit has three phalanges. But, on the right, the same digit has two phalanges. The first metacarpal bone articulates with os multangulum majus; however, the second metacarpal articulates with the extra one on the left hand. The first and second metatarsals articulate with os multangulum majus on the right. The row of carpal bones are normal on both hands.

Fig. 4. The radiograph of the feet of IV.7. The first os cuneiformis is duplicated on both feet. The second and third metatarsals of the right foot come together on the metatarsophalangeal articulatio.
Fig. 5. 13-year-old male, IV.11. The radiographs of the feet. The first os cuneiformis is duplicated on both feet.

Fig. 6. 7-year-old boy, IV.14. The radiographs of the feet. The first toes are amputated. There are the enlarged first metatarsals on both feet.

Fig. 7. Male at age 6 months, IV.17. The radiograph of the left hand. There is a distal phalanx on the first digit and a bony remnant instead of well-developed first metacarpal.

Fig. 8. Radiographs of the feet of IV.17. These are distally displaced and similar in the length of the first and second metatarsals on both feet.

TABLE

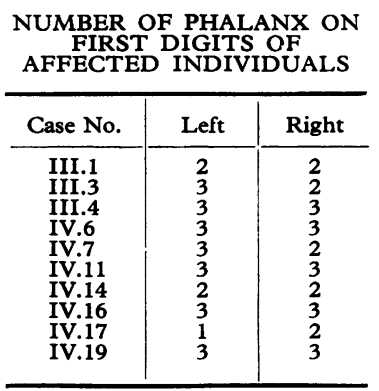




\section{APPENDIX 2}

\section{Dermatoglyphs of individuals with index finger polydactyly}
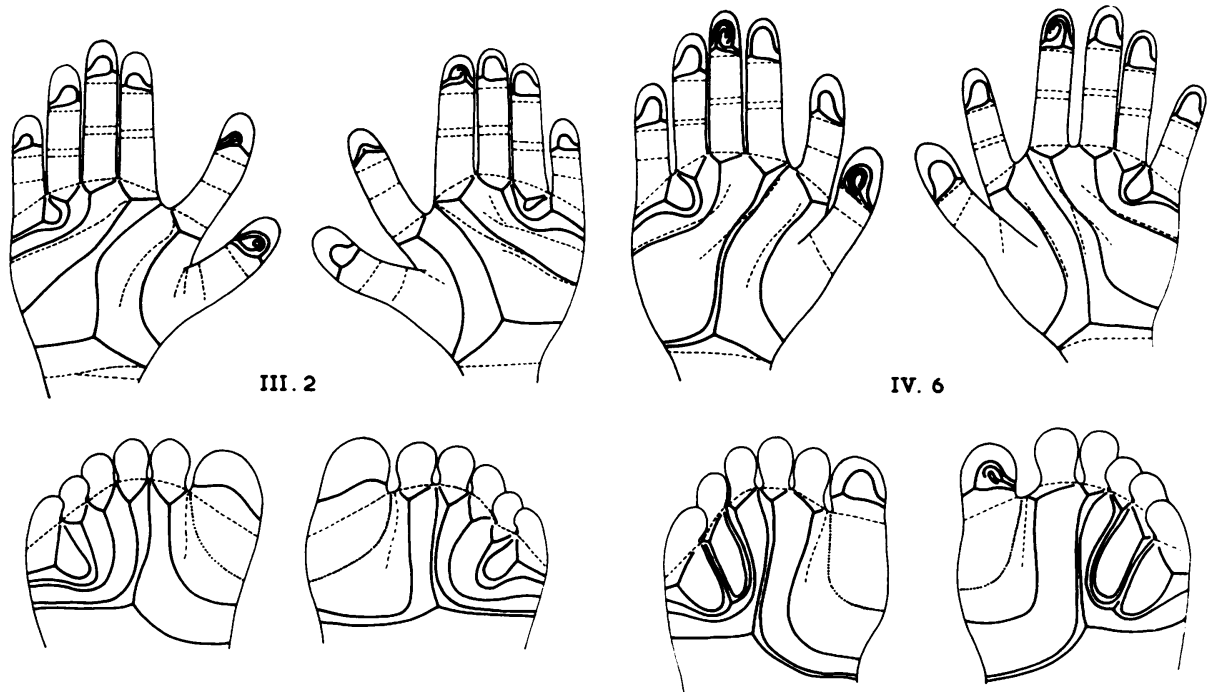

FIG. 1. The digital type and main lines of hands and feet of III.2 and IV.6.
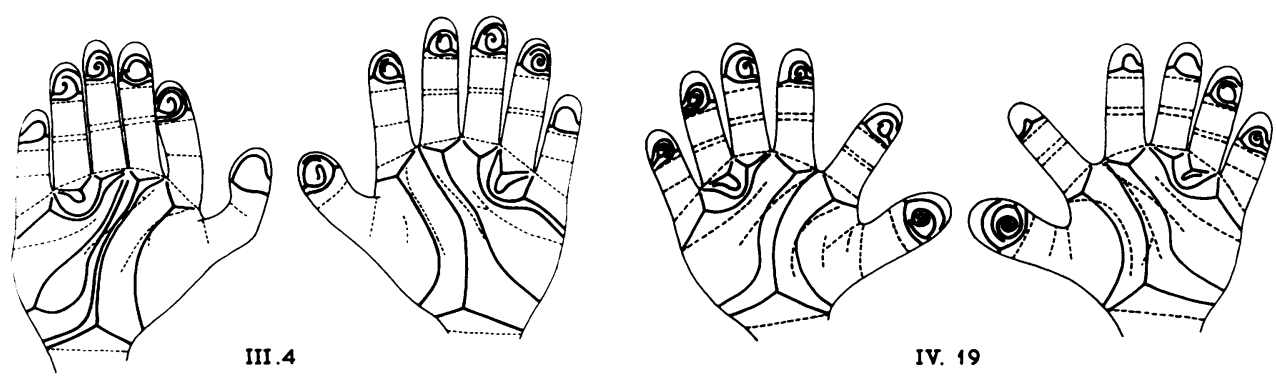

IV. 19
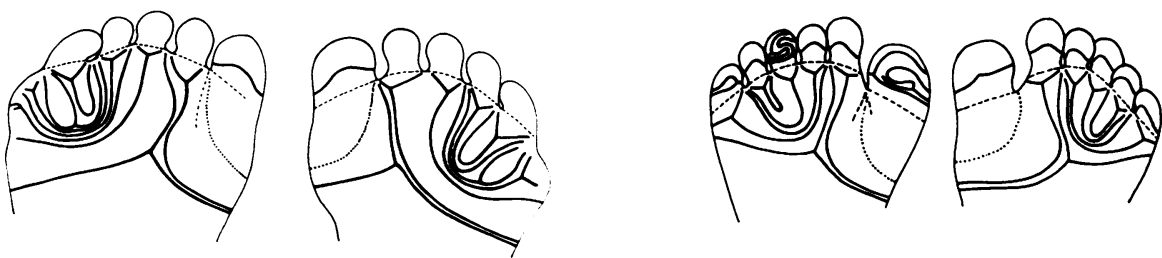

FIG. 2. The digital type and main lines of the hands and feet of III.4 and IV.19. 


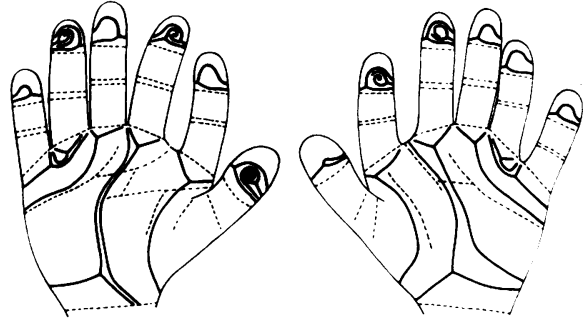

III.3


IV. 11
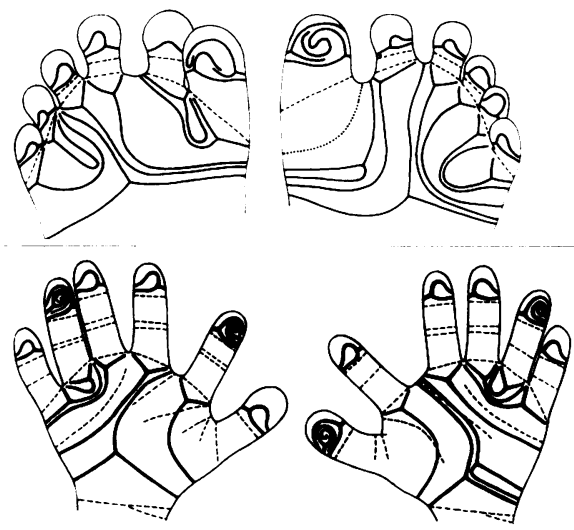

IV. 16

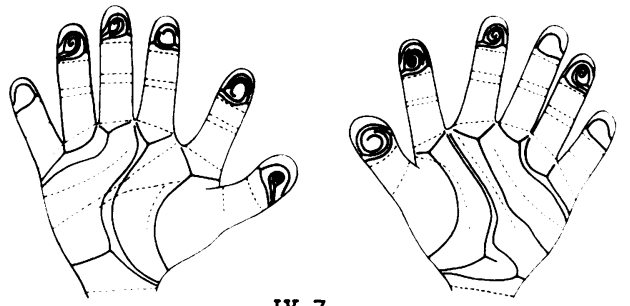

IV. 7
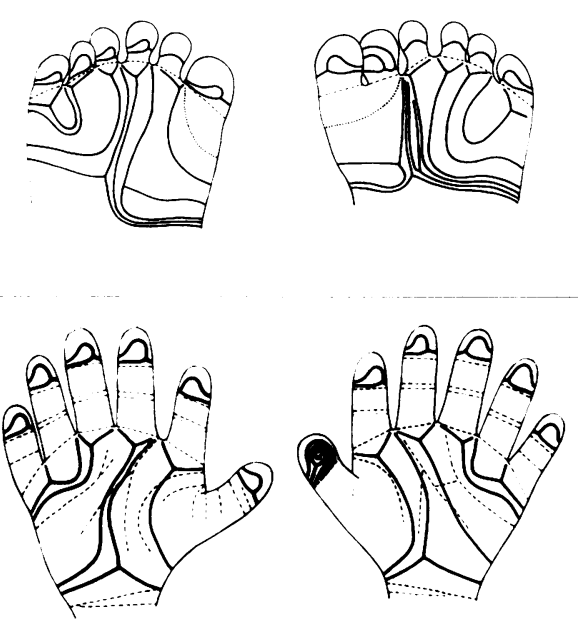

IV. 14


IV. 17
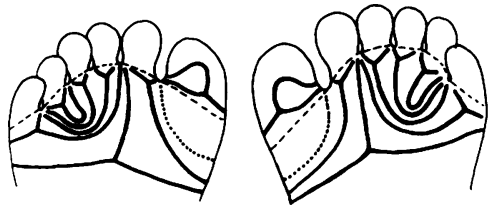

FIG. 3. The digital type and main lines of the hands and feet of III.3, IV.7, IV.11, IV.14, IV.16, and IV.17. 